\title{
Study of the cytotoxic and irritant effects of skin cleansing soaps
}

\author{
Juan P. Castanedo-Cázares, Juan D. Cortés-García, Mayra F. Cornejo-Guerrero, \\ Bertha Torres-Álvarez and Diana Hernández-Blanco* \\ Dermatology Department, Hospital Central "Dr. Ignacio Morones Prieto", Universidad Autónoma de San Luis Potosí, San Luis Potosí, Mexico
}

\begin{abstract}
Background: The use of soap for skin cleansing is common among the population. However, it is possible that it causes damage to skin cells and disrupts the skin barrier. Objective: To determine the cytotoxic effect of soaps on in vitro-cultured keratinocytes and to correlate it with clinical irritation. Method: A survey was conducted to find out the most widely used commercial soaps and their number. Subsequently, their cytotoxicity was evaluated in human keratinocyte cultures using the resazurin assay. The soaps with the highest and lowest cytotoxicity were applied to the skin of healthy volunteers to assess their effect on the skin barrier using colorimetry and transepidermal water loss (TEWL) assays. Results: Of the analyzed soaps, $37 \%$ were shown to be toxic to keratinocytes in vitro. The soap with the highest toxicity induced the highest rate of erythema and TEWL, in comparison with the least toxic soap and the vehicle used as the control solution. Conclusion: Soaps marketed for skin cleansing can contain chemical ingredients that damage human keratinocytes and cause skin barrier subclinical irritation. Their use can worsen preexisting dermatoses, generate xerotic or irritant contact dermatitis, and cause atrophy and dermatoporosis.
\end{abstract}

KEY WORDS: Cytotoxicity. Soap. Erythema. Transepidermal water loss.

\section{Estudio del efecto citotóxico e irritativo de jabones para la limpieza cutánea}

\section{Resumen}

Introducción: El jabón para el aseo cutáneo es de empleo común entre la población, sin embargo, es posible que cause daño a las células de la piel y modifique la barrera cutánea. Objetivo: Determinar el efecto citotóxico de los jabones en queratinocitos cultivados in vitro y correlacionarlo con la irritación clínica. Método: Se realizó una encuesta para conocer los jabones comerciales más utilizados y su cantidad; posteriormente, se evaluó su citotoxicidad en cultivos de queratinocitos humanos mediante el método de resazurina. Los jabones con mayor y menor citotoxicidad se aplicaron en piel de voluntarios sanos para evaluar su efecto en la barrera cutánea mediante ensayos de colorimetría y pérdida transepidérmica de agua. Resultados: De los jabones analizados, 37 \% demostró ser tóxico para los queratinocitos in vitro. El jabón con mayor toxicidad indujo el mayor índice de eritema y pérdida transepidérmica de agua, en comparación con el jabón menos tóxico y el vehículo empleado como solución control. Conclusión: Los jabones comercializados para el aseo cutáneo pueden incluir ingredientes químicos que dañan los queratinocitos humanos y causan irritación subclínica de la barrera cutánea. Su utilización puede agravar dermatosis preexistentes, generar dermatitis xerósica o de contacto irritativa y causar atrofia y dermatoporosis.

PALABRAS CLAVE: Citotoxicidad. Jabón. Eritema. Pérdida de agua transepidérmica.

\footnotetext{
Correspondence:

*Diana Hernández-Blanco

E-mail: dvianey55@ hotmail.com

Gac Med Mex. 2020;156:418-423

Contents available at PubMed

www.gacetamedicademexico.com

0016-3813/@ 2020 Academia Nacional de Medicina de México, A.C.. Published by Permanyer. This is an open access article under the CC BY-NC-ND license (http://creativecommons.org/licenses/by-nc-nd/4.0/).
} 


\section{Introduction}

Skin-cleansing soap is of common use in our society. This product constitutes a mixture of fatty acid salts that are able to form mycelia when combined with lipophilic substances in an aqueous medium. ${ }^{1}$ Due to this chemical property, soaps extract the lipid content from the stratum corneum and favor its dissolution. ${ }^{2}$ Superficial removal of this layer implies elimination of exogenous pollutants, reduction of odors, and modification of the skin microbiota; ${ }^{3}$ however, excessive or repeated use of soap can damage the skin barrier, with the consequent exposure of epidermal keratinocytes to the chemical components of the product. Stratum corneum physiological pH ranges between 4.5 and 5 , but soap can alkalize it. ${ }^{4}$ Disruption of the skin lipid structure causes irritation, oxidative stress and inflammation; ${ }^{5}$ clinical manifestations include contact dermatitis accompanied by redness, scaling, itching, and exudate. Under experimental conditions, it is possible to detect subclinical inflammation within four hours after soap was in contact with the skin surface. ${ }^{6}$

In addition to the irritant nature of soap, the surfactants derived from these compounds are toxic to keratinocytes. ${ }^{7}$ Cytotoxicity is defined as any alteration of basic cell functions caused by contact with some chemical compound. ${ }^{8}$ Skin irritation caused by soap is evaluated by means of in vivo tests that assess clinical and physiological parameters, such as increased blood flow ${ }^{6}$ and epidermal water evaporation. ${ }^{9}$ Soap cytotoxic effect is quantified in keratinocyte cultures by means of cell damage, death, proliferation, or metabolism modification assays. ${ }^{8}$

In clinical practice, it is common to observe adverse effects due to excessive and continuous use of soaps for skin cleansing, usually in children and older adults, as well as in individuals with different inflammatory dermatoses.

Whether the cytotoxic effect of the chemical ingredients of soaps marketed in Mexico participates in the manifestations related to stratum corneum aggression is not known; therefore, the purpose of this work was to determine the irritating and cytotoxic effect of a sample of commercially-available soaps in Mexico, and to analyze their possible relationship.

\section{Method}

From April to August 2017, 300 consecutive attendants to the dermatology department of the "Dr. Ignacio Morones Prieto" Central Hospital, in San Luis Potosí, were interviewed with regard to the use of soap for personal hygiene. Based on the provided information, the eight commercial products most widely used by the attendants, as well as by 30 healthy volunteers who agreed to participate and provided written informed consent, were selected. People aged $>30$ years without skin, mental or systemic diseases were included. The study was approved by the ethics committee of the hospital with registry number 2217.

\section{Cytotoxicity assay}

- Cell culture. Human keratinocytes (HaCaT cells) were cultured in $25-\mathrm{cm}^{2}$ culture plates in RPMI1640 medium supplemented with $10 \%$ fetal bovine serum, penicillin (1000 IU/mL) and streptomycin $(10 \mathrm{mg} / \mathrm{mL})$; incubation was carried out at $37{ }^{\circ} \mathrm{C}$ with $5 \% \mathrm{CO}_{2}$. Subcultures were carried out when $80 \%$ confluence was achieved. The cells were harvested with trypsin/EDTA $(0.1 \%)$ for 10 minutes, re-suspended in RPMI-1640 medium, and centrifuged at $1500 \mathrm{rpm}$ for 5 minutes. Consecutive subcultures were divided at a 1:3 ratio.

- Emulsion preparation. Once the cell culture was obtained, it was exposed to emulsions of the selected soaps, the amount of which was determined by estimating the actual use, for which the difference of the soap bar dry weight was measured before and after hand washing. 2-mg/mL emulsions of the soap samples were prepared in normal saline solution, which were identified using code numbers (1 to 8); $\mathrm{pH}$ was measured with a Thermo Electron Orion $410 \mathrm{~A}^{\circledast}$ potentiometer (Cole-Parmer, IL, USA). The assays were carried out in a blinded fashion.

- Viability assay. Cell viability was quantified using the resarzurin assay. After being harvested, $3 \times 10^{4}$ cells were transferred to 96 -well plates and cultured for 24 hours. Subsequently, the medium was removed to add each soap solution for 10 minutes, and then the cells were washed with phosphate-buffered saline solution. Finally, the cells were cultured in RPMI medium with $20 \mu \mathrm{g} / \mathrm{mL}$ of resarzurin for two hours. Fluorescence was quantified with a spectrofluorometer at $530 \mathrm{~nm}$ excitation/590 emission. The negative controls were the culture medium, and saline was used as vehicle. $0.3 \%$ water was used as positive control.

\section{Irritation clinical study}

The soap solutions with the highest and lowest in vitro viability were used, as well as placebo (normal 
Table 1. Chemical constituents of the assessed skin cleansing products

\begin{tabular}{|c|c|c|}
\hline Product/manufacturer & pH & Formulation \\
\hline 1. Zest ${ }^{\circledast}$ (Unilever) & 9.8 & $\begin{array}{l}\text { Sodium oleate/palmitate/laurate, corn starch, water, glycerin, perfume, lauric acid, sodium chloride, } \\
\text { sodium citrate, citric acid, EDTA, tetrasodium etidronate, PEG-45M, silica, Cocos nucifera water, } \\
\text { Litchi chinencis fruit extract, DMDM hydantoin, geraniol. }\end{array}$ \\
\hline 2. Neutro Balance ${ }^{\circledast}$ (Colgate) & 9.7 & $\begin{array}{l}\text { Sodium oleate/palmitate/laurate, glycerin, water, sodium dodecylbenzenesulfonate, cocamide } \\
\text { MEA, fragrance, cocamidopropyl betaine, titanium dioxide (CI77891), tetra-di-t-butyl } \\
\text { hydroxyhydrocinnamate, pentasodium pentetate. }\end{array}$ \\
\hline 3. Dove ${ }^{\circledR}$ (Unilever) & 7.4 & $\begin{array}{l}\text { Sodium lauroyl, isethionate, stearic acid, sodium palmitate, lauric acid, water, sodium isethionate, } \\
\text { sodium stearate, cocamidopropyl betaine, sodium palm kernelate, glycerin, perfume, sodium } \\
\text { chloride, zinc oxide, EDTA, tetrasodium etidronate, alumina, alpha-isomethyl ionone, benzyl alcohol, } \\
\text { butylphenyl methylpropional, citronellol, coumarin, hexyl cinnamic, limonene, linalool. }\end{array}$ \\
\hline 4. Lipikar ${ }^{\circledast}$ (La Roche Posay) & 9.6 & $\begin{array}{l}\text { Sodium palmate, sodium stearate, sodium cocoate, water, glycerin, titanium dioxide (Cl77891), } \\
\text { EDTA, etidronic acid, salicylic acid, sodium chloride, zinc PCA (C36985/1). }\end{array}$ \\
\hline 5. Cleanance ${ }^{\circledast}$ (Avene) & 6.8 & $\begin{array}{l}\text { Sodium lauryl sulfosucinate, maltodextrin, sodium cocoyl isethionate, stearic acid, water, cetearyl } \\
\text { alcohol, paraffin, thermal water, shea butter, ceteareth-6, Prunus amygdalus dulcis oil, citric acid, } \\
\text { microcrystalline wax, polyethylene, serine, titanium dioxide (CI77891). }\end{array}$ \\
\hline 6. Kleenex ${ }^{\circledR}$ (Kimberly-Clark) & 10.3 & $\begin{array}{l}\text { Sodium tallowate, sodium cocoate, water, glycerin, mineral oil, fragrance, sodium chloride, titanium } \\
\text { dioxide, sodium hydroxide, EDTA, etidronic acid, amorphous silica, aluminum hydroxide, coconut } \\
\text { and almond cream aroma. }\end{array}$ \\
\hline 7. Escudo ${ }^{\circledast}$ (Kimberly-Clark) & 10.0 & $\begin{array}{l}\text { Sodium oleate, sodium palmitate, water, sodium stearate, glycerin, sodium laureate, sodium } \\
\text { myristate, sodium linoleate, sodium palmitoleate, fragrance, sodium chloride, titanium dioxide } \\
\text { (Cl77891), zinc pyrithione, sodium hydroxide, EDTA, etidronic acid, aluminum oxide, green } 3 \\
\text { (Cl42053), red } 33 \text { (Cl17200). }\end{array}$ \\
\hline 8. Camay ${ }^{\circledR}$ (Unilever) & 9.7 & $\begin{array}{l}\text { Sodium oleate/palmitate/laurate, cornstarch, water, glycerin, perfume, lauric acid, sodium chloride, } \\
\text { sodium citrate, citric acid, titanium dioxide, PEG-45M, silica, hydrolyzed silk, rose flower extract, } \\
\text { Jasminum officinale flower extract, Prunus amygdalus dulcis oil, Nelumbium speciosum flower oil, } \\
\text { Mentha arvensis leaf oil, Cymbopogon Martini oil, EDTA, tetrasodium etidronate, DMDM hydantoin, } \\
\text { cinnamic hexyl, benzyl alcohol, benzyl salicylate, citronellol, eugenol, hydroxycitronellal, limonene, } \\
\text { linalool, Cl } 14700 .\end{array}$ \\
\hline
\end{tabular}

saline solution), which were applied to the volar portion of the left forearm using Finn chambers. Skin evaluation was carried out prior to the application and after 10,30 and 60 minutes.

Irritation was quantified by trans-epidermal water loss in $\mathrm{g} / \mathrm{cm}^{2}$, and erythema, using the CIELAB color space $\mathrm{a}^{*}$ axis, with possible values ranging from 0 to 50. The equipment used was an evaporimeter (Dermalab $^{\circledR}$, Cortex, Denmark) and a diffuse reflectance colorimeter (CR- $400^{\circledR}$, Minolta, Japan). The measurements were obtained in facilities at a controlled temperature of $21{ }^{\circ} \mathrm{C}$ and relative humidity of $70 \%$.

\section{Statistical analysis}

A sample of 30 people was calculated to detect a difference of 0.2 in trans-epidermal water loss between the soap emulsion and the negative control, assuming a deviation of 20 , a two-tailed $95 \%$ confidence interval, an $\alpha$-value of 0.05 and power of 0.8 .
For descriptive analyses, central tendency measures were used. The differences between groups were analyzed with ANOVA and Kruskal-Wallis test, as well as post hoc analysis with Dunn's test. The Prisma GraphPad $^{\circledR}$ program, version 5.0 (San Diego CA), was used. A $p$-value $<0.05$ was considered significant.

\section{Results}

The $\mathrm{pH}$ and ingredients of the soaps most widely used by the surveyed population are included in table 1 . The clinical study included 30 people with an average age of 41 years, with a range of 30 to 50 . Twelve men and 18 women were included. Phototype was III in seven volunteers, IV in 14, and V in nine.

\section{Cytotoxicity}

Keratinocyte viability was modified by some of the studied soap solutions, with the negative control 


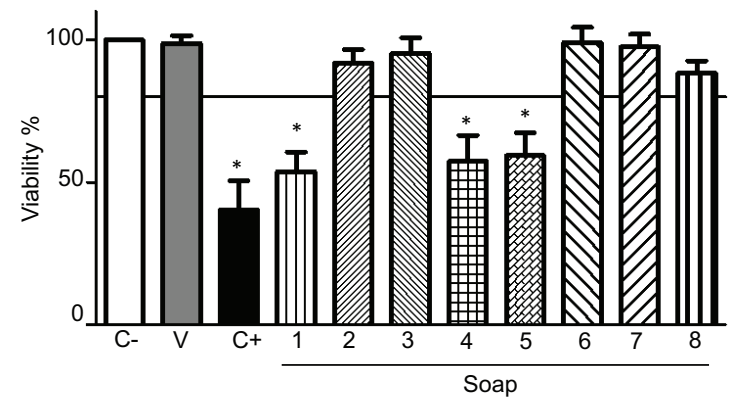

Figure 1. Cytotoxic effect of soaps on keratinocyte cultures. Viability percentage of keratinocyte cultures exposed to soap solutions using the rezasurin assay. The culture medium was used as negative control (C-), normal saline solution as the vehicle (V), and $0.3 \%$ of water as positive control (C+). The horizontal black line indicates $80 \%$ viability, which represents the cytotoxic effect threshold. The results correspond to the mean $\pm S D$ of five cultures carried out in duplicate. *Significant difference versus negative control $(p<0.05$; ANOVA).

taken as reference (ANOVA, $\mathrm{p}=0.001)$. Soaps 1,4 , and 5 decreased keratinocyte viability, in contrast with soaps 2, 3, 6, 7 and 8, which did not modify them (Fig. 1).

\section{Skin irritation}

- Trans-epidermal water loss. Regarding the results of the cytotoxicity assay, solutions 1 and 2 were evaluated in vivo due to their lower and higher cell viability in vitro, respectively. At $10 \mathrm{~min}$ of their application, both soaps showed an increase in trans-epidermal water loss (ANOVA, $p=0.01$ ); however, solution 1 showed higher evaporation versus solution 2 and the vehicle. After 60 minutes, the skin exposed to all three solutions returned to its baseline values, as shown in figure 2.

- Colorimetry. Erythema was quantified using CIELAB color space $a^{*}$ axis value. Soap solution 1 increased baseline values from $8.4 \pm 0.7$ to 8.8 $\pm 0.7,9.1 \pm 0.5$ and $9.2 \pm 0.4$ at 10,30 and 60 minutes, respectively (ANOVA, $p=0.01$ ). Solution 2 and the vehicle showed no significant changes (Fig. 3).

\section{Discussion}

The use of soap is essential for hygiene of the Mexican population. Excessive or continuous use of these product has been shown to generate stress, irritation and inflammation in the skin, which in clinical practice

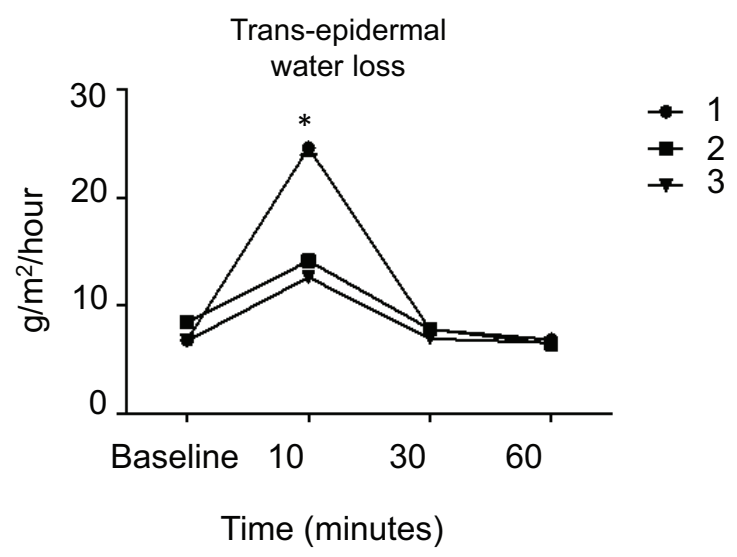

Figure 2. The most cytotoxic soap caused skin irritation in healthy subjects. Levels of trans-epidermal water loss in non-photo-exposed skin of healthy subjects, with the most cytotoxic (1) and least cytotoxic (2) soap solution; measurements at baseline and 10, 30 and 60 minutes after soap exposure. Normal saline solution was used as control vehicle $(V)$. The results correspond to the mean $\pm S D$ of 30 subjects. *Significant difference versus the other groups ( $p<0.05$; ANOVA).

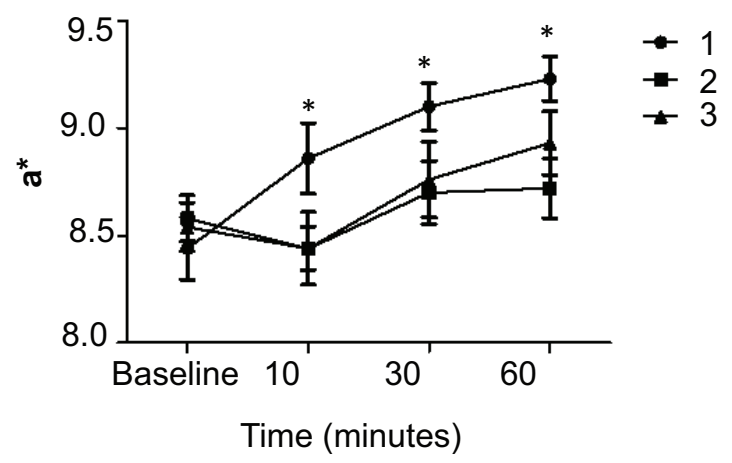

Figure 3. Erythema quantified using the CIELAB color space $a^{*}$ axis value in non-photo-exposed skin of healthy subjects. Curves for the most and least cytotoxic soap solution (1 and 2 respectively) are shown at baseline and after 10, 30 and 60 minutes of exposure. Normal saline solution was used as control vehicle (V). The results correspond to the mean $\pm S D$ of 30 volunteers. *Significant difference versus the other groups $(p<0.05$, ANOVA).

is typified as contact dermatitis. ${ }^{10}$ The effects of soap on the skin have been associated with its ability to modify the stratum corneum $\mathrm{pH},{ }^{11}$ as well as with the toxic effect of its ingredients on epidermal cells. ${ }^{7}$ Soap is considered a cosmetic product and, in Mexico, it is regulated by the Federal Commission for Protection against Sanitary Risks (COFEPRIS - Comisión Federal para la Protección contra Riesgos Sanitarios), and the Federal Bureau for Consumer Protection (PROFECO - Procuraduría Federal del Consumidor). The legal framework for its commercialization is 
established by Official Mexican Standard NOM-039SSA1-1993, Goods and Services. Perfumery and Beauty Products. Determination of Eye and Primary Dermal Irritation and Sensitization Indices, as well as NOM-141-SSA1-1995, Goods and Services. Labeling for Pre-packaged Perfumery and Beauty Products. Given that these are not products subjected to pharmacovigilance, the noxious effect of these chemical compounds on the skin of the Mexican population was unknown.

The cytotoxicity assays showed that $37 \%$ of the analyzed soaps reduced keratinocyte viability, after exposure under conditions comparable to those of usual hand washing or body shower. Therefore, it could be speculated that prolonged exposure, and a higher concentration might generate higher toxicity. ${ }^{9}$ In this work, $\mathrm{pH}$ did not show a relationship with soap toxic effect, unlike findings in other investigations that associate it with the capability to directly generate clinical irritation. ${ }^{4,11}$ Regarding toxicity induction, we are not certain which substance or chemical substances of the products are the culprits; however, the noxious effect could be related to the surfactants that are used. ${ }^{7}$ This hypothesis is based on the fact that several ingredients of the products that caused cytotoxicity were also present in those that did not (e.g., preservatives, colorants, humectants), and we only found variations in the type of surfactant. In our sample, the products with the highest toxicity contained anionic surfactants, which have been described as more aggressive to the skin surface. ${ }^{12}$ The least toxic products combined anionic and amphoteric surfactants, which could have favored higher cell viability. ${ }^{2}$

Unlike the less toxic soaps, the soap with the highest cytotoxicity generated greater irritation, which was assessed by water loss and skin erythema. In this research, the skin was exposed to the skin cleanser during a period similar to usual hand washing in Mexico, which is a short period in comparison with those analyzed in other studies. ${ }^{6}$ During that interval, the soap was able to dissolve stratum corneum lipids, penetrate and affect epidermal keratinocytes, which confirms the findings of other analyses where skin cleansing in a single event induces stratum corneum dehydration. ${ }^{13,14}$ Biophysical parameters normalization was detected up to 60 minutes after exposure. This finding is important, since in patients with a higher predisposition for suffering dermatosis with alterations in the skin barrier such as atopic dermatitis, xerosis, or ichthyosis, the recovery period could be longer. ${ }^{15}$
Based on our findings, repeated cleansing with soap before the barrier function is restored might favor chronic skin dysfunction in the Mexican population. ${ }^{9,16}$ Although demonstrating this was not the purpose of this study, frequent use of these products might contribute to a continuous or intermittent occurrence of irritant contact dermatitis, as well as tissue changes that are clinically expressed as skin aging, given that the toxic effect on cells increases oxidative stress, which damages DNA, and decreases cell repair mechanisms, thus favoring their premature death. ${ }^{17-19}$

Some limitations of this work include that only bar soaps were analyzed, and not gel, foam or liquid presentations. Neither were all commercially-available products included, but rather those referred by a population-based sample as the most widely consumed. On the other hand, it will be interesting knowing if there is a difference between presentation, price and quantity of these products with regard to their toxic effect, as well as their noxious effect in patients with specific skin conditions, such as atopic dermatitis.

\section{Conclusion}

Our study provides evidence on the relationship between the in vitro-determined toxic activity of some soaps for commercial use in Mexico and the subclinical alterations they originate in vivo, detected after a relatively brief contact period and quantified by biophysical methods; restoration of the skin barrier was observed up to one hour later.

We noticed that, depending on the frequency and quantity of product employed, the use of soap for skin cleansing might have implications for skin health, by favoring the appearance, exacerbation or persistence of inflammatory dermatoses, as well as by inducing acute or chronic degenerative processes.

\section{Acknowledgements}

We thank Dr. Iván Nelinho Pérez Maldonado from the Molecular Toxicology Laboratory of the Coordination for Science and Technology Innovation and Application (National Laboratory, CONACYT), for providing the necessary infrastructure for the development of this project.

\section{Conflict of interests}

The authors declare that there is no conflict of interest 


\section{Funding}

This study was financed with resources from the Dermatology Department of the "Dr. Ignacio Morones Prieto" Central Hospital of San Luis Potosí, Mexico.

\section{Ethical disclosures}

Protection of human and animal subjects. The authors declare that the procedures followed adhered to the ethical standards of the responsible human experimentation committee and were in agreement with the World Medical Association and the Declaration of Helsinki.

Confidentiality of data. The authors declare that they followed the protocols of their work center on the publication of patient data.

Right to privacy and informed consent. The authors declare that no data regarding the voluntary participants appear in this article.

\section{References}

1. Shahinuzzaman M, Yaakob Z, Moniruzzaman M. Medicinal and cosmetics soap production from Jatropha oil. J Cosmet Dermatol. 2016;15:185-193.

2. Yokoi A, Endo K, Ozawa T, Miyaki M, Matsuo K, Nozawa K, et al. A cleanser based on sodium laureth carboxylate and alkyl carboxylates washes facial sebum well but does not induce dry skin. J Cosmet Dermatol. 2014;13:245-252

3. Hovi T, Ollgren J, Savolainen-Kopra C. Intensified hand-hygiene campaign including soap-and-water wash may prevent acute infections in office workers, as shown by a recognized-exposure -adjusted analysis of a randomized trial. BMC Infect Dis. 2017;17:1-9.

4. Baranda L, González-Amaro R, Torres-Álvarez B, Álvarez C, Ramírez V. Correlation between $\mathrm{pH}$ and irritant effect of cleansers marketed for dry skin. Int J Dermatol. 2002;41:494-499.
5. Han H, Roan F, Ziegler SF. The atopic march: current insights into skin barrier dysfunction and epithelial cell-derived cytokines. Immunol Rev. 2017;78:116-130

6. Khosrowpour Z, Nasrollahi SA, Ayatollahi A, Samadi A, Firooz A. Effects of four soaps on skin trans-epidermal water loss and erythema index. $J$ Cosmet Dermatol. 2018;18:857-861.

7. Korting HC, Herzingera T, Hartingerb A, Kerschera M, Angerpointner T, Maibachd $\mathrm{HI}$. Discrimination of the irritancy potential of surfactants in vitro by two cytotoxicity assays using normal human keratinocytes, HaCaT cells and 3T3 mouse fibroblasts: Correlation with in vivo data from a soap chamber assay. J Dermatol Sci. 1994:7:119-129.

8. CSA [Internet]. ISO 10993-5:2009. Biological evaluation of medical devices - Part 5: Tests for in vitro cytotoxicity; 2009.

9. Williams C, Wilkinson M, McShane P, Pennington D, Fernandez C, Pierce S. The use of a measure of acute irritation to predict the outcome of repeated usage of hand soap products. Br J Dermatol. 2011;164:1311-1315.

10. Warren R, Ertel KD, Bartolo RG, Levine MJ, Bryant PB, Wong LF. The influence of hard water (calcium) and surfactants on irritant contact dermatitis. Contact Dermatitis. 1996;35:337-343.

11. Gonçalves GM, Brianezi G, Miot HA. The pH of the main Brazilian commercial moisturizers and liquid soaps: considerations on the repair of the skin barrier. An Bras Dermatol. 2017;92:376-378.

12. Draelos Z, Hornby S, Walters RM, Appa Y. Hydrophobically modified polymers can minimize skin irritation potential caused by surfactant-based cleansers. J Cosmet Dermatol. 2013;12:314-321.

13. Moore PN, Shiloach A, Puvvada S, Blankschtein D. Penetration of mixed micelles into the epidermis: effect of mixing sodium dodecyl sulfate with dodecyl hexa (ethylene oxide). J Cosmet Sci. 2003:54:143-159.

14. Bornkessel A, Flach M, Arens-Corell M, Elsner P, Fluhr JW. Functional assessment of a washing emulsion for sensitive skin: Mild impairment of stratum corneum hydration, $\mathrm{pH}$, barrier function, lipid content, integrity and cohesion in a controlled washing test. Skin Res Technol. 2005;11:53-60.

15. Del Rosso JQ, Levin J. The clinical relevance of maintaining the functional integrity of the stratum corneum in both healthy and disease-affected skin. J Clin Aesthet Dermatol. 2011;4:22-42.

16. Grunewald AM, Gloor M, Gehring W, Kleesz P. Damage to the skin by repetitive washing. Contact Dermatitis. 1995:32:225-232.

17. Zijno A, De Angelis I, De Berardis B, Andreoli C, Russo MT, Pietraforte D, et al. Different mechanisms are involved in oxidative DNA damage and genotoxicity induction by $\mathrm{ZnO}$ and $\mathrm{TiO} 2$ nanoparticles in human colon carcinoma cells. Toxicol In Vitro. 2015;29:1503-1512.

18. Tyagi N, Srivastava SK, Arora S, Omar Y, ljaz ZM, Al-Ghadhban A, et al. Comparative analysis of the relative potential of silver, zinc-oxide and titanium-dioxide nanoparticles against UVB-induced DNA damage for the prevention of skin carcinogenesis. Cancer Lett. 2016;383:53-61.

19. Du J, Wang S, You H, Jiang R, Zhuang C, Zhang X. Developmental toxicity and DNA damage to zebrafish induced by perfluorooctane sulfonate in the presence of ZnO nanoparticles. Environ Toxicol. 2016;31:360-371. 